\title{
PERANCANGAN KAMPANYE PENTINGNYA SARAPAN SEHAT UNTUK ANAK-ANAK SEKOLAH DASAR DI SURABAYA
}

\author{
Vina Valencia, \\ Benny Rahmawan Noviadji. \\ Institut Informatika Indonesia (IKADO), Surabaya \\ vinavalencia93@gmail.com
}

\begin{abstract}
Abstrak
Anak-anak sering terlihat lemas, mengantuk, kurang konsentrasi, sakit perut dan bahkan maag pada pagi hari. Kesibukan orang tua di pagi hari seringkali melupakan sarapan untuk anak-anak mereka. Padahal, sarapan pagi sangat penting sebagai sumber energi saat beraktivitas di sekolah. Sosialiasi atau pemahaman kepada anak-anak mengenai pentingnya sarapan sehat sangat diperlukan. Salah satu solusinya adalah dengan mengadakan kampanye. Oleh karena itu, sebagai sarana edukasi dan informasi yang efektif mengenai pentingnya sarapan sehat, perlu dibuat kampanye sarapan sehat yang menarik, menyenangkan dan mendidik untuk anak-anak sekolah dasar, orang tua serta guru. Dengan menggunakan film animasi 2D sebagai media utama beserta media pendukungnya. Sehingga, mampu memberikan pengaruh yang baik bagi anak-anak sekolah dasar agar bisa beraktivitas dan belajar dengan baik. Selain itu juga sebagai wacana penyadaran kepada orang tua dan guru tentang pentingnya sarapan.
\end{abstract}

Kata kunci: kampanye, kesehatan, animasi, film.

\begin{abstract}
Children often look weak, feel sleepy, lack of concentration, abdominal pain, and even gastric pains in the morning. With the busyness of parents in the morning, they often forget about breakfast for their children. In fact, breakfast is very important as an energy source during activity at school. Socializing or understanding toward the children about the importance of healthy breakfast is required. One of them is by holding a campaign. Therefore, as a means of effective education and information about the importance of healthy breakfast, there's need to be made an interesting, fun, and educational campaign for elementary school children, parents, and teachers. By using $2 D$ animation film as the main media and its media supporters. Thus, able to give a good influence for elementary school children in order for them to indulge and learn well. In addition, as a mean of awareness to parents and teachers about the importance of breakfast.
\end{abstract}

Keywords: campaign, healthy, animation, film. 


\section{PENDAHULUAN}

Sebelum mengawali hari, sarapan diperlukan agar tubuh dapat beraktivitas dengan baik. Terutama bagi anak-anak sekolah yang perlu belajar dan beraktivitas dengan baik di sekolah. Kesibukan orang tua di pagi hari, seringkali melupakan sarapan untuk anak-anak mereka. Padahal, sarapan pagi sangat penting sebagai sumber energi saat beraktivitas di sekolah. Gizi yang baik untuk sarapan juga tidak diperhatikan atau kurangnya pengetahuan akan hal gizi. Sarapan yang sehat tentu akan membawa pola hidup yang sehat pula, anak menjadi sehat, cerdas dan aktif di sekolah.

Dalam Jurnal Gizi dan Pangan oleh Fachrudin Perdana \& Hardiansyah (2013) menyatakan bahwa lebih dari separuh (69.6\%) subjek anak Indonesia masih belum mengonsumsi sarapan sesuai dengan anjuran gizi seimbang. Dibuktikan juga dalam jurnal penelitian Wardoyo (2013) dari Fakultas Kesehatan Masyarakat, Universitas Airlangga Surabaya menyatakan bahwa responden yang tidak terbiasa sarapan pagi sebagian besar $(87,5 \%)$ memiliki konsentrasi yang rendah. Penyuluhan atau sosialisasi mengenai kesehatan terutama sarapan, perlu diadakan di sekolah agar anak-anak dapat mengerti pentingnya sarapan sehat. Salah satunya yaitu dengan mengadakan kampanye. Namun yang sering terjadi, kampanye yang diadakan sekolah ternyata masih kurang optimal, sehingga murid merasa bosan dan informasi tidak tersampaikan dengan baik. Oleh karena itu perlu dibuat kampanye sarapan sehat yang menarik, menyenangkan dan mendidik untuk anak-anak sekolah dasar, orang tua serta guru.

Dari pemahaman dan penjelasan di atas, maka dapat ditarik inti permasalahan yaitu sebagai berikut: 1) Kurangnya kesadaran anak-anak akan pentingnya sarapan; 2) Sekolah jarang memberikan penyuluhan sosial/ sosialisasi tentang kesehatan khususnya tentang pentingnya sarapan pagi; 3) Kurangnya kesadaran orang tua akan pentingnya sarapan dan gizi sarapan yang baik untuk anak-anak; 4) Masih ada orang tua yang jarang menyiapkan sarapan yang teratur bagi anak mereka; 5) Perilaku anak saat sarapan kurang baik; 6) Anak-anak sering mengantuk dan lemas pada pagi hari dikarenakan tidak sarapan pagi; 7) Kampanye yang diadakan selama ini kurang optimal; 8) Anak-anak Sekolah Dasar cenderung menyukai film animasi. 
Penelitian ini bertujuan sebagai sarana edukasi dan informasi yang efektif mengenai pentingnya sarapan pagi, sehingga mampu memberikan pengaruh yang baik bagi anak-anak sekolah agar menjadi semakin semangat dan lebih konsentrasi di sekolah, serta menjadi orang yang cerdas dan aktif. Selain itu juga sebagai wacana penyadaran kepada orang tua dan guru tentang pentingnya sarapan.

\section{KAJIAN TEORI}

\section{Teori Pentingnya Sarapan Sehat}

Anak seharusnya dibiasakan untuk makan pagi sebelum pergi ke sekolah karena makan pagi sangat penting untuk memberikan nutrisi yang dibutuhkan oleh tubuh untuk bekerja dan belajar. Makanan merupakan bahan bakar yang penting bagi anak untuk bisa beraktivitas dari pagi di sekolah, layaknya bensin sebagai bahan bakar yang dibutuhkan sebuah mobil untuk bisa berjalan.

Masa kanak-kanak pertengahan yaitu usia 6 sampai 12 tahun sering disebut sebagai "usia sekolah". Pada tahap ini terjadi perkembangan fisik, mental dan sosial yang berkelanjutan disertai penekanan pada perkembangan kompetensi keterampilan. Periode ini merupakan periode kritis dalam perkembangan konsep diri dan intelektual (Wong, 2009). Pada masa ini dibutuhkan asupan nutrisi yang kuat untuk menghindari masalah-masalah yang dapat mengganggu pertumbuhan dan perkembangan mereka sehingga memungkinkan pertumbuhan fisik dan perkembangan otak menjadi optimal (Suyatno, 2009). Anak dengan status gizi kurang ataupun lebih dapat menyebabkan terganggunya pertumbuhan, terhambatnya perkembangan intelektual, menurunnya kekebalan tubuh sehingga dapat dengan mudah terserang berbagai penyakit.

\section{Teori Kampanye}

Kampanye adalah keinginan seseorang atau sekelompok orang untuk mempengaruhi kepercayaan dan tingkah laku orang lain dengan daya tarik yang komunikatif. Adapun tujuan dari kampanye adalah menciptakan "perubahan" atau "perbaikan" di dalam masyarakat. Bila dalam suatu lingkungan sosial terjadi perubahan atau perbaikan maupun perkembangan, kemungkinan besar "kampanye telah berlangsung di lingkungan tersebut dan apabila dalam suatu lingkungan sosial terjadi perubahan atau perbaikan maupun perkembangan, kemungkinan besar 
"kampanye telah berlangsung di lingkungan tersebut. (Rice \& Paisley dalam Rumanti: 2005). Sedangkan menurut Rogers dan Storey dalam Venus (2004: 7) kampanye sebagai "serangkaian tindakan komunikasi yang terencana dengan tujuan untuk menciptakan efek tertentu pada sejumlah besar khalayak yang dilakukan secara berkelanjutan pada kurun waktu tertentu.

\section{METODE PENELITIAN}

Sebagai bentuk penelusuran terhadap permasalahan yang terjadi, maka dilakukan sejumlah penelitian. Penelitian yang dilakukan yaitu melalui: 1) Mengidentifikasi fenomena dan problematika; 2) Studi kompetitor dan studi komparator. Studi kompetitor dilakukan terhadap kampanye sarapan sehat di kampus Institut Pertanian Bogor (IPB) dan kampanye sarapan sehat di Gedung Serbaguna Kali Code di Yogyakarta. Studi komparator dilakukan terhadap kampanye "Pekan Sarapan Nasional" dengan Nestle tahun 2014, kampanye "Pekan Sarapan Nasional" dengan Blue Band tahun 2014 dan Kampanye "Share Breakfast" dari Kellogg's; 3) Hasil wawancara kepada murid dan guru di beberapa sekolah dasar di Surabaya. Wawancara kepada murid bertujuan untuk meneliti kebiasaan anak-anak SD pada pagi hari, khususnya sarapan. Wawancara kepada guru bertujuan untuk menggali dampak dari fenomena anak yang lemas dan mengantuk di pagi hari. 4) Hasil wawancara dengan dokter untuk mengetahui pola sarapan sehat bagi anak, manfaat yang didapat dan dampaknya bagi anak yang tidak sarapan; 5) Studi literatur dan teori yang berhubungan dengan penelitian; 6) Hasil dari kuesioner untuk mengidentifikasi masalah.

\section{HASIL DAN PEMBAHASAN}

\section{Proses dan Konsep}

Konsep perancangan kampanye ini diperoleh dari keyword. Keyword diperoleh dari hasil fenomena, inti masalah, positioning dan target audiens serta AIO. Sehingga diperoleh keyword yang sesuai yaitu educative dan entertaining. Dalam perancangan ini, sisi edukatif diterapkan melalui konsep komunikasi dan informasi yang terkandung dalam media utama hingga media promosi. Sisi hiburan terlihat dari segi visual mulai dari warna, tipografi, tipe karakter dan gaya desain. 
Proses perancangan media utama yaitu film animasi 2D yang diawali dengan pembuatan naskah cerita. Kemudian dilakukan pembuatan storyboard sehingga dapat diketahui karakter-karakter yang diperlukan. Karakter utama terdiri dari Superhero, Andi, Dina, Bon-Bon dan Neo. Kemudian, untuk melengkapi perancangan media utama diperlukan pula karakter figuran, logo kampanye, logo superhero dan setting (background). Tahapan dari proses desain adalah sketsa alternatif, digital alternatif, desain terpilih, hingga desain final. Berikut adalah proses sketsa karakter:

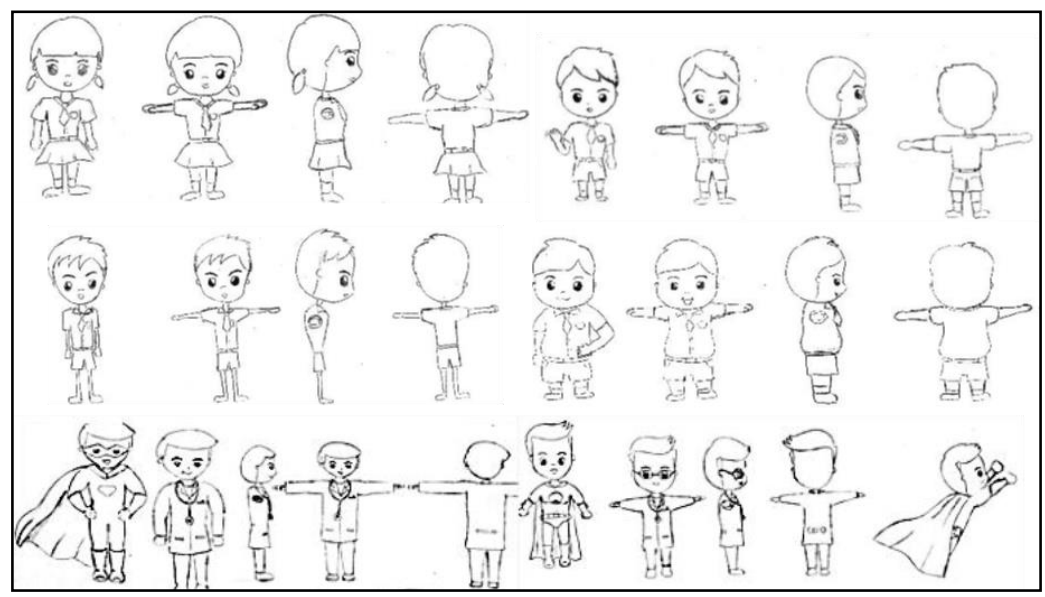

Gambar 1. Sketsa Karakter Utama

Sumber: Dokumentasi Penulis

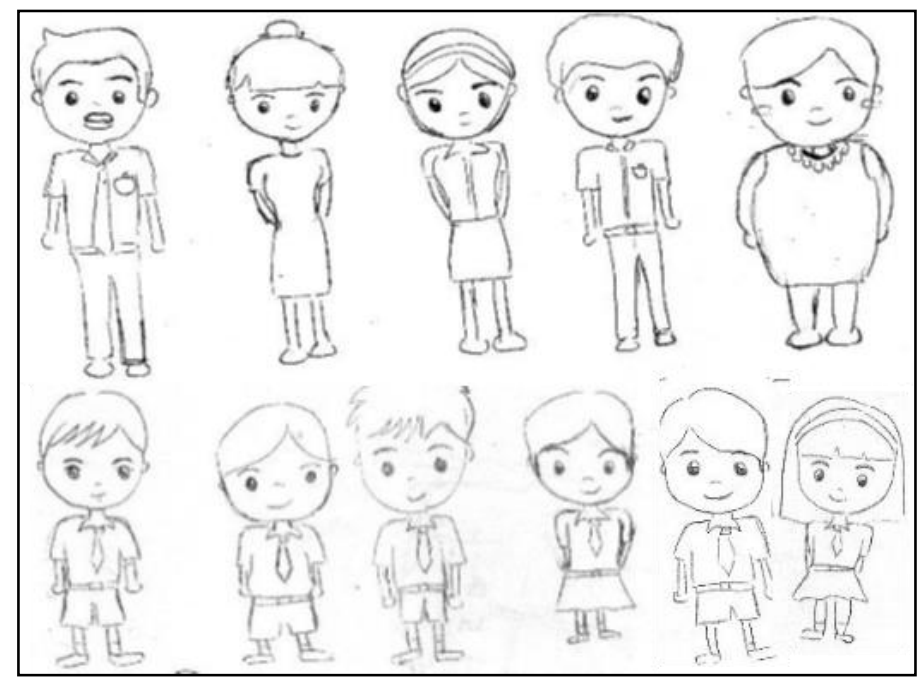

Gambar 2. Sketsa Karater Figuran

Sumber: Dokumentasi Penulis 


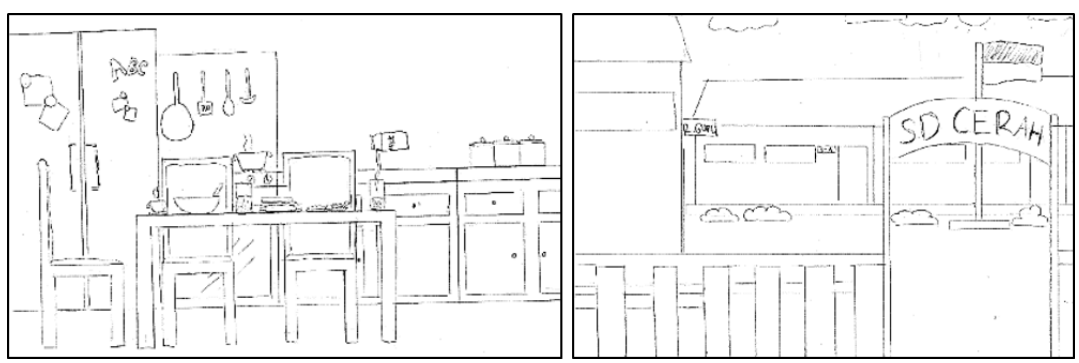

Gambar 3. Sketsa Setting Background

Sumber: Dokumentasi Penulis

Proses pemilihan nama Bfast berawal dari brainstorming dan mind mapping, kemudian tercipta beberapa alternatif nama yang disortir sehingga hanya menjadi satu desain terpilih. Nama Bfast berasal dari kata breakfast yang berarti sarapan. Arti Bfast sendiri adalah menjadi cepat mengandung arti cepat dan sigap dalam memberikan pertolongan.

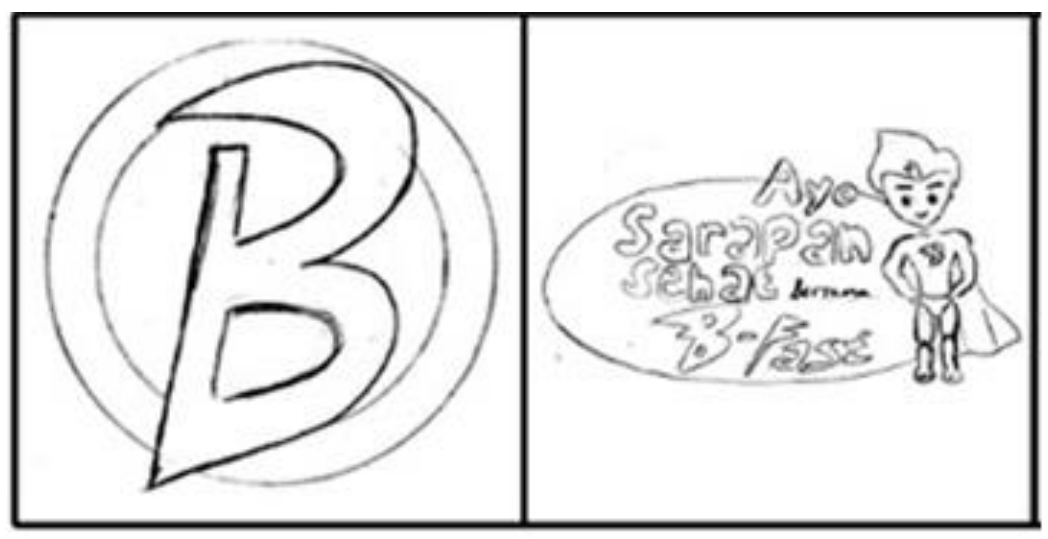

Gambar 4. Sketsa alternatif logo kampanye dan superhero Sumber: Dokumentasi Penulis

Pada proses digital alternatif, hasil sketsa kemudian diseleksi dan diproses menjadi desain digital. Pada proses ini desain banyak mengalami revisi mulai dari bentuk, detail, warna dan lain-lain. Pada tahap desain terpilih, desain yang telah direvisi disempurnakan lagi dan terdapat penambahan atau pengurangan detail. Pada tahap terakhir proses perancangan media utama film animasi 2D ini, desain terpilih yang telah mengalami revisi diperbaiki dan disempurnakan kembali agar hasilnya sesuai dengan konsep dan tujuan perancangan. Berikut adalah kumpulan desain final: 


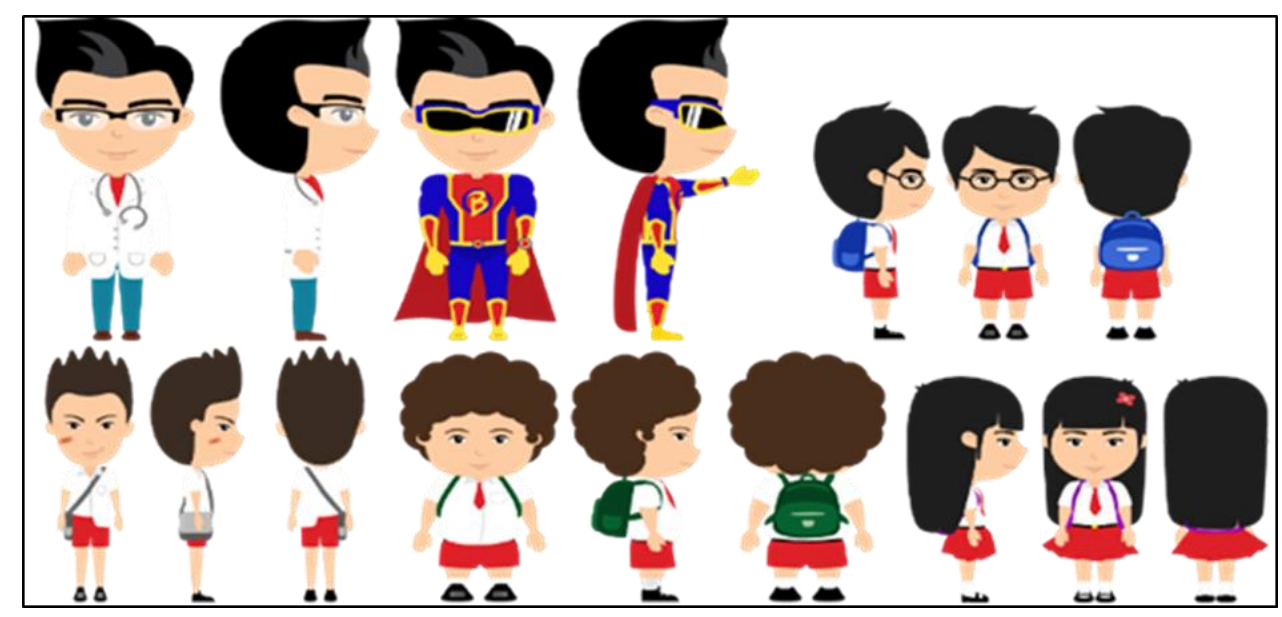

Gambar 5. Desain Final Karakter Utama

Sumber: Dokumentasi Penulis

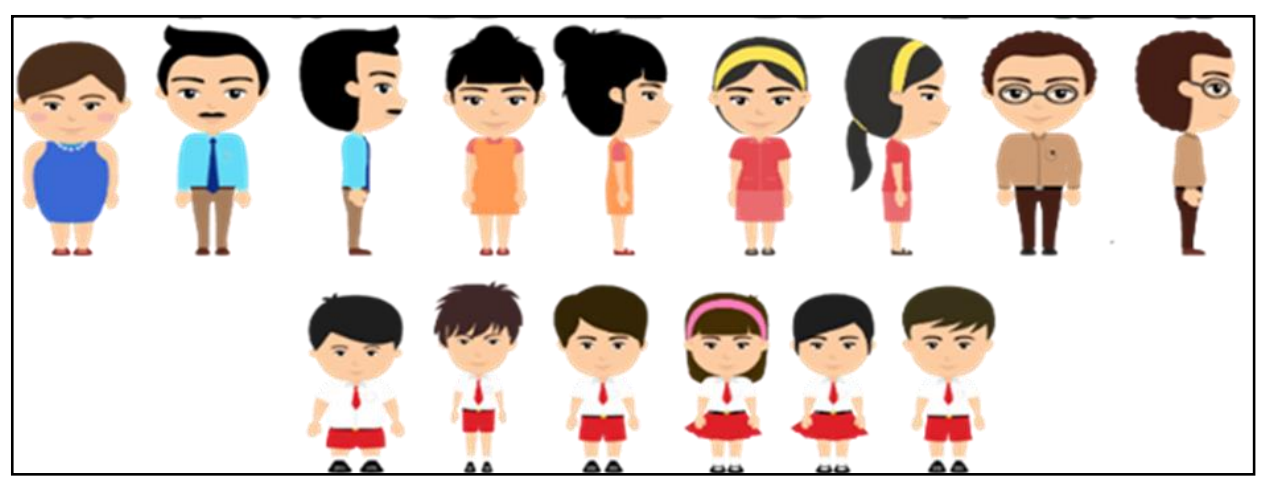

Gambar 6. Desain Final Karaker Figuran

Sumber: Dokumentasi Penulisan

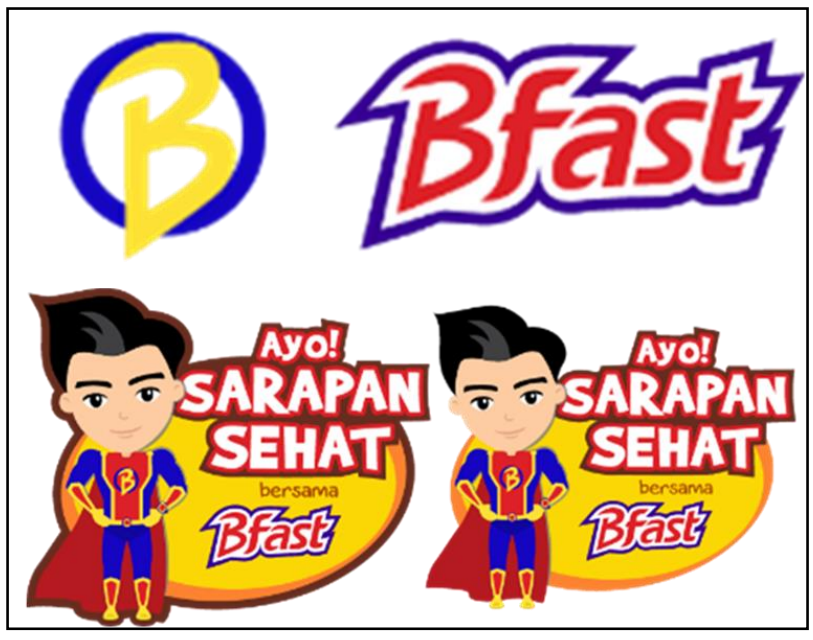

Gambar 7. Desain Final Logo

Sumber: Dokumentasi Penulisan 

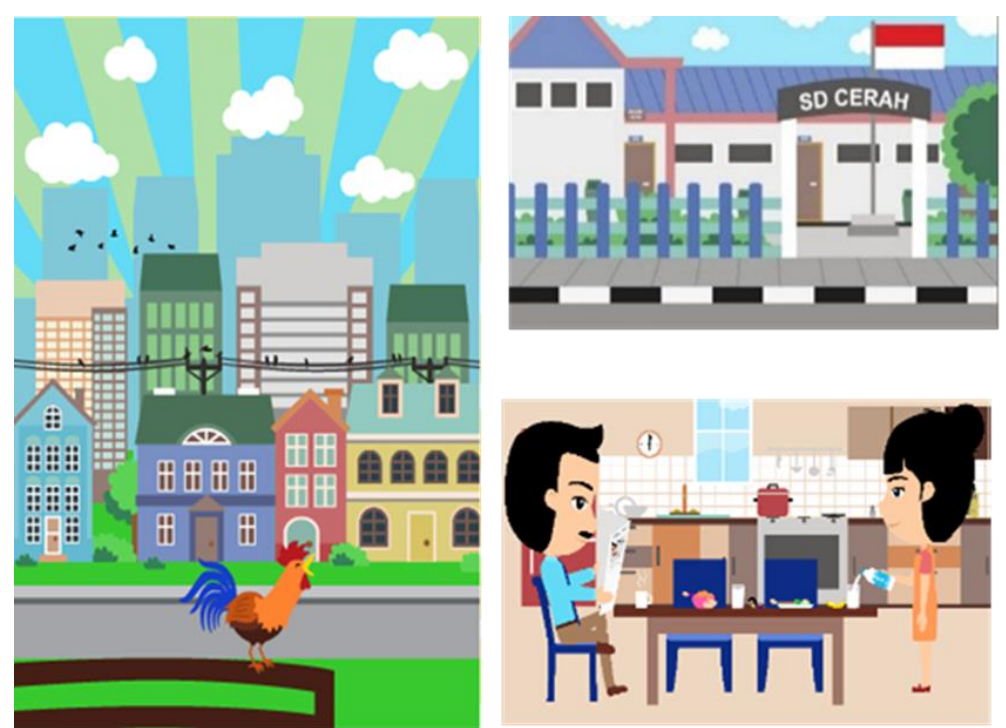

Gambar 8. Desain Final Setting Background Sumber: Dokumentasi Penulisan

\section{Desain Final}

Sebagai pelengkap perancangan kampanye ini, diperlukan media pendukung yaitu: media perlengkapan event dan media promosi. Media perlengkapan event digunakan untuk mendukung jalannya acara sekaligus memeriahkan acara. Terdiri dari: merchandise, souvenir, banner, brosur, dan umbul-umbul. Media promosi digunakan untuk promosi kepada masyaraklat luas

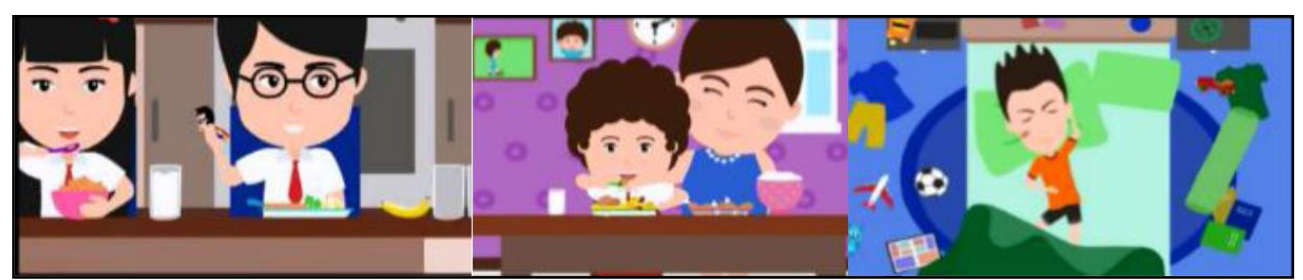

Gambar 9. Adegan Perkenalan Karater Andi, Dina, Bon-bon, Neo. Sumber: Dokumentasi Penulis

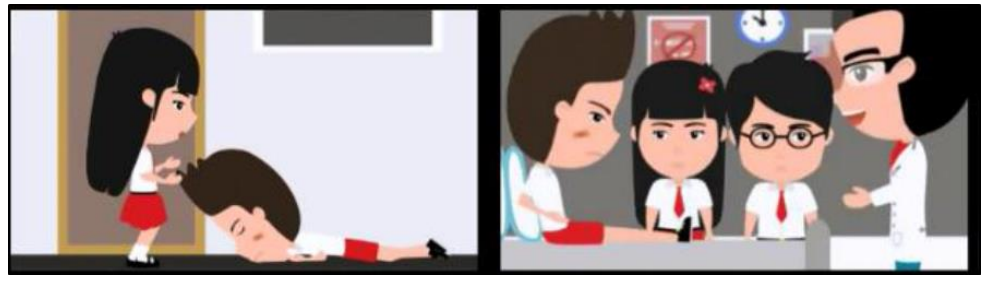

Gambar 10. Adegan Neo pingsan karena tidak sarapan pagi Sumber: Dokumentasi Penulis 


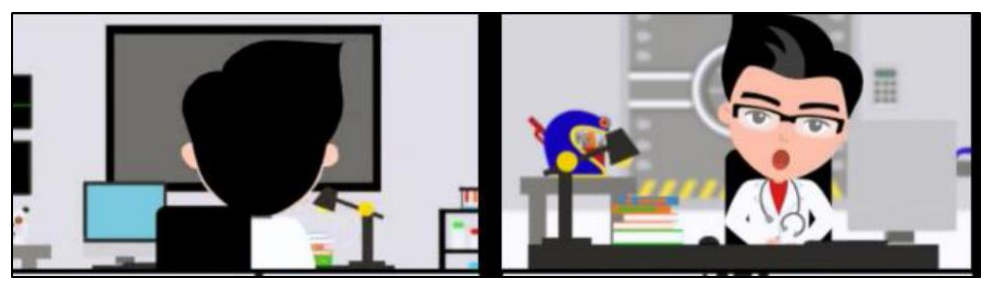

Gambar 11. Adegan perkenalan Dr.Beni atau Bfast Sumber: Dokumentasi Penulis

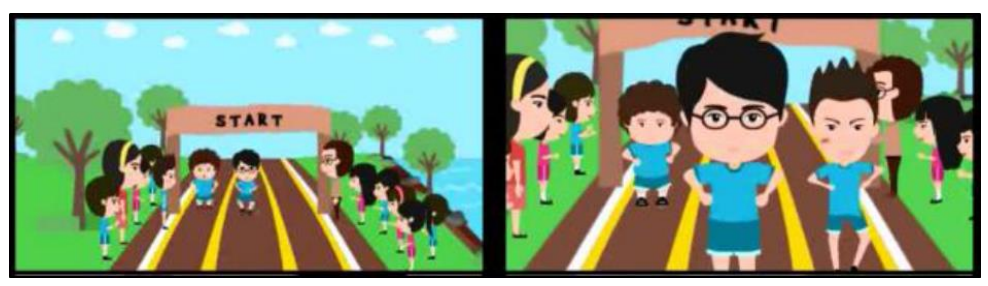

Gambar 12. Adegan keesokan hari lomba lari Sumber: Dokumentasi Penulis

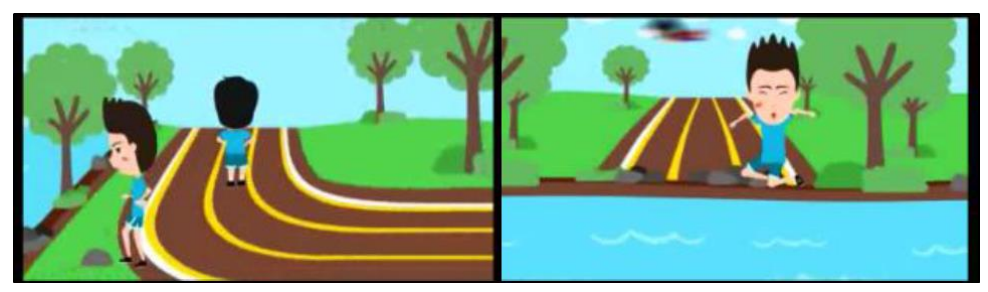

Gambar 13. Adegan Neo berniat jahat dan terjatuh ke sungai Sumber: Dokumentasi Penulis

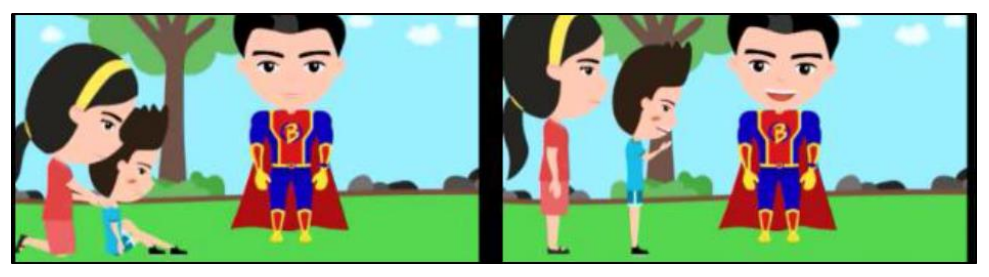

Gambar 14. Adegan Bfast menolong dan menasihati Sumber: Dokumentasi Penulis

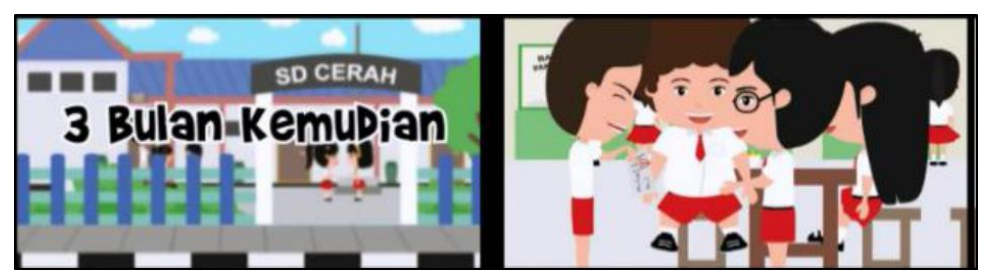

Gambar 15. Adegan epilog,

Neo mendapat nilai bagus karena sarapan sehat

Sumber: Dokumentasi Penulis 


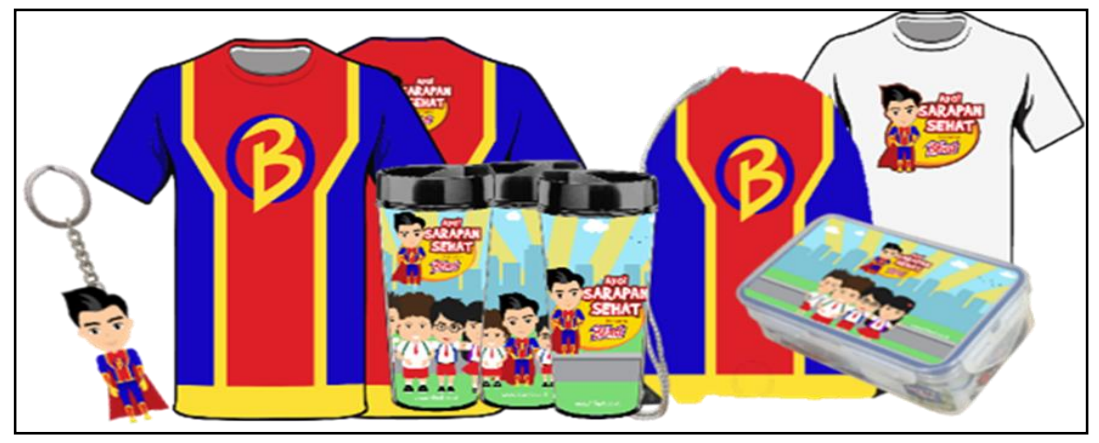

Gambar 16. Desain final merchandise

Sumber: Dokumentasi Penulis

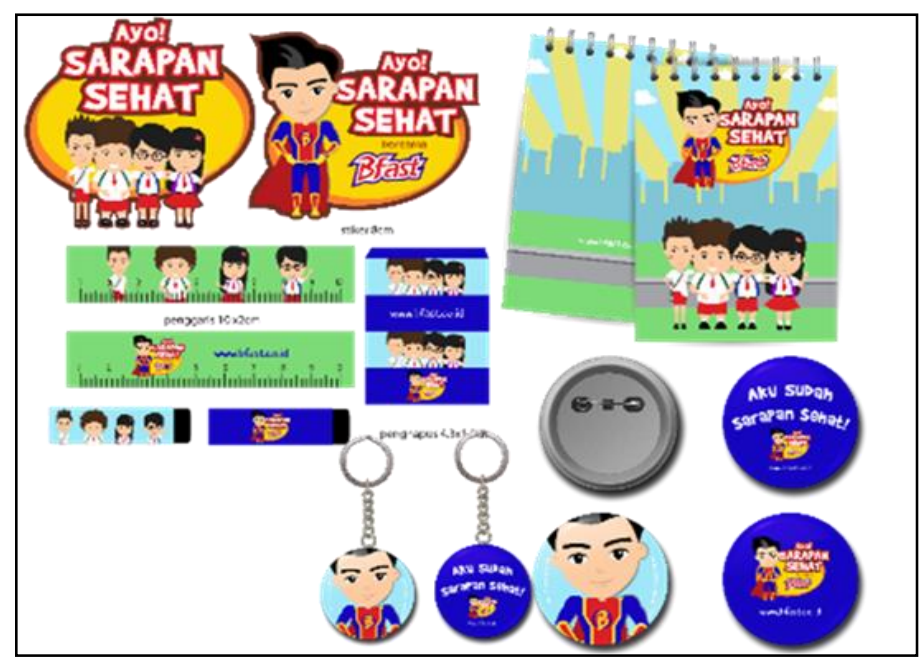

Gambar 17. Desain final souvenir

Sumber: Dokumentasi Penulis

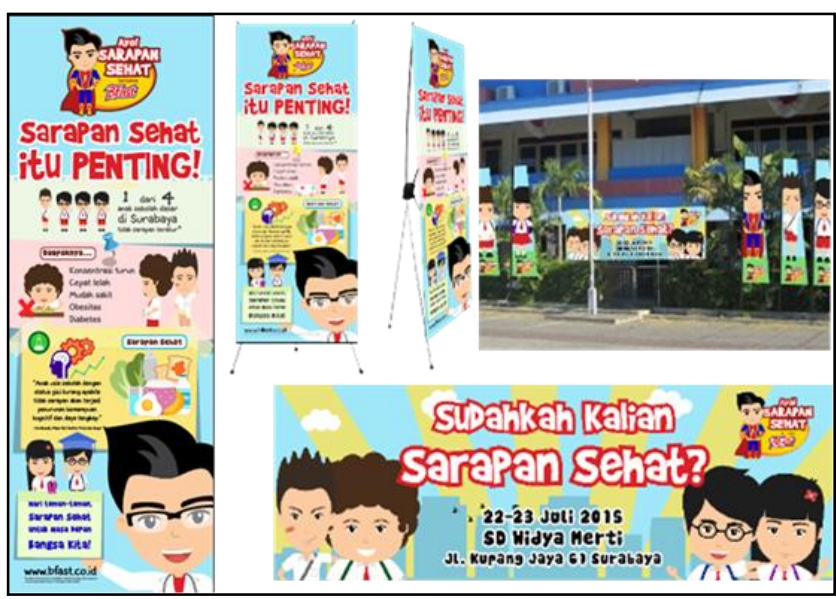

Gambar 18. Desain final banner

Sumber: Dokumentasi Penulis 


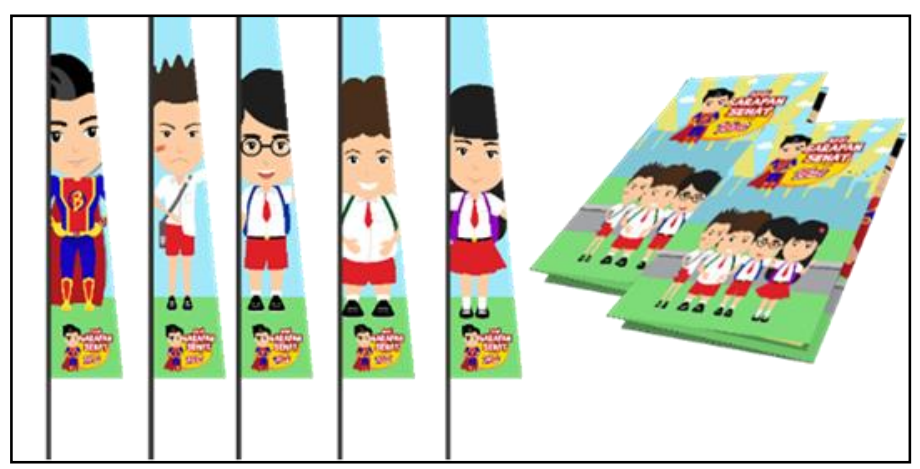

Gambar 19. Desain final umbul-umbul (kiri) dan brosur (kanan)

Sumber: Dokumentasi Penulis

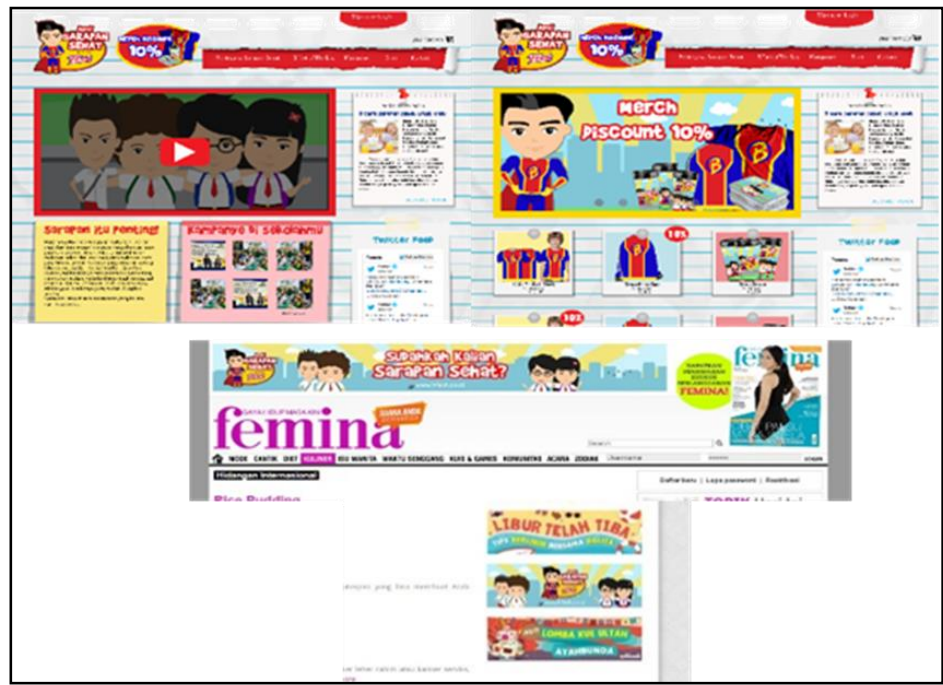

Gambar 20. Desain final website (atas)

dan web banner (bawah)

Sumber: Dokumentasi Penulis

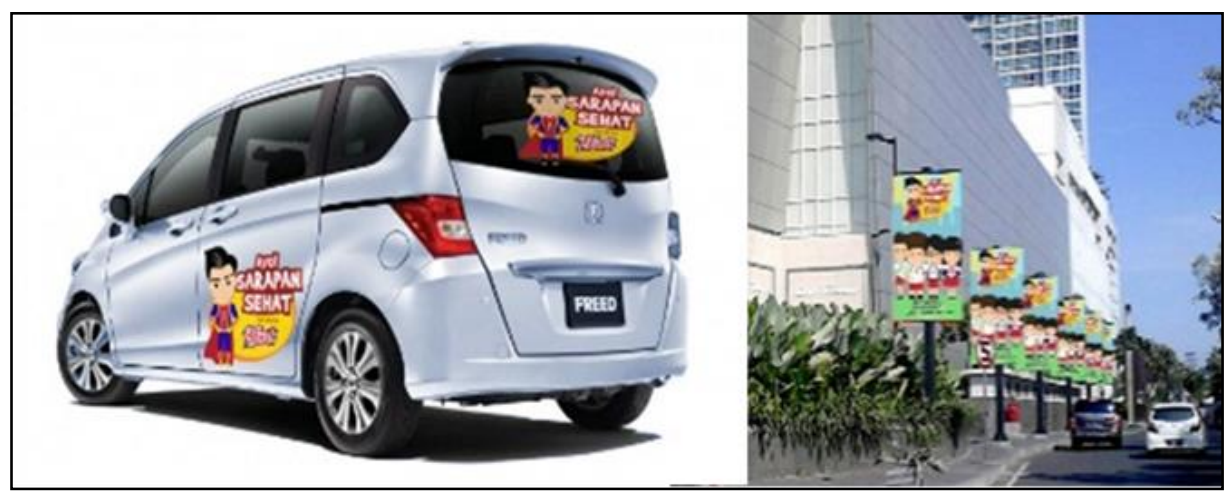

Gambar 21. Desain final transit ad (kiri) dan street banner (kanan)

Sumber: Dokumentasi Penulis 


\section{SIMPULAN DAN SARAN}

\section{Simpulan}

Sebelum mengawali hari, sarapan diperlukan agar tubuh dapat beraktivitas dengan baik. Terutama bagi anak-anak sekolah yang perlu belajar dan beraktivitas dengan baik di sekolah. Dari hasil penelitian yang dilakukan berupa wawancara, kuesioner, identifikasi masalah dan observasi, diketahui bahwa sebanyak $26 \%$ orang tua jarang hingga tidak pernah menyiapkan sarapan untuk anak mereka. Berdasarkan hasil wawancara kepada guru-guru sekolah dasar di Surabaya, menyatakan bahwa belum ada kampanye yang menyinggung tentang pentingnya sarapan pagi.

Oleh karena itu, perlu dibuat kampanye mengenai pentingnya sarapan sehat yang menarik, menyenangkan dan mendidik untuk anak-anak sekolah dasar, orang tua serta guru. Dari hasil penelitian yang dilakukan, ditemukan bahwa film animasi 2D merupakan media utama yang paling efektif untuk anak-anak sekolah dasar. Selain mempunyai kekuatan visual yang menarik, film animasi dapat ditangkap lebih baik oleh anak-anak. Informasi dan edukasi dikemas dalam suasana hiburan menjadi lebih mudah tersampaikan. Tidak hanya film animasi 2D sebagai media utama, namun kampanye perlu didukung dengan media pelengkap agar informasi dan edukasi pentingnya sarapan sehat semakin melekat di benak peserta. Media promosi juga diperlukan agar masyarakat luas dapat mengetahui pentingnya sarapan sehat. Harapannya adalah anak-anak menjadi semakin mengerti pentingnya sarapan sehat. Orang tua juga semakin sadar akan pentingnya sarapan sehat dan rutin untuk mengingatkan anak-anak mereka. Sekolah dan guru menjadi semakin peduli terhadap murid-murid yang tidak sarapan sehat.

\section{Saran}

Sarapan yang sehat diperlukan bagi anak-anak agar mereka dapat belajar dan beraktivitas dengan baik. Sudah seharusnya, para orang tua mulai membiasakan anak mereka sarapan sehat sejak dini. Anak-anak juga dibiasakan untuk sarapan bergizi dan tidak pilah-pilih makanan. Anak-anak tidak hanya akan menjadi lebih sehat, tetapi juga akan meningkatkan prestasi belajar. Dengan adanya anak-anak yang sering terlihat lemas dan mengantuk di sekolah karena tidak sarapan pagi, sekolah seharusnya lebih peduli dan aktif mengadakan sosialisasi mengenai 
pentingnya sarapan sehat. Sosialisasi atau kampanye yang dilakukan harus lebih menarik dan sesuai dengan daya tangkap anak-anak. Media dan konsep kampanye harus lebih menarik agar anak-anak tidak cepat melupakannya

\section{DAFTAR PUSTAKA}

Antar, Venus. (2004). Manajemen Kampanye; Panduan Teoritis Dan Praktis Dalam Mengefektifkan Kampanye Komunikasi. Bandung: Simbiosa Rekaatam Media

Perdana, Fachruddin dan Hardinsyah. (2013). "Analisis Jenis, Jumlah, dan Mutu Gizi Konsumsi Sarapan Anak Indonesia”. Jurnal Gizi Dan Pangan. Vol. 8. No. 1. 2013. Hal 42-43.

Rumanti, M.A. (2005). Dasar-dasar Public Relations: Teori dan Praktik, Edisi ketiga. Jakarta: Raja Grasindo Persada.

Suyatno. (2009). Penentuan Status Gizi. Semarang: FKM Undip.

Wardoyo, Hanum Aprilia dan Trias Mahmudiono. 2013. "Hubungan Makan Pagi dan Tingkat Konsumsi Zat Gizi dengan Daya Konsentrasi Siswa Sekolah Dasar". Media Gizi Indonesia. Vol. 9. No.1. 2013. Hal 49-53.

Wong, Donna L. (2009). Buku Ajar Keperawatan Pediatrik, Edisi 6. Jakarta: EGC. 